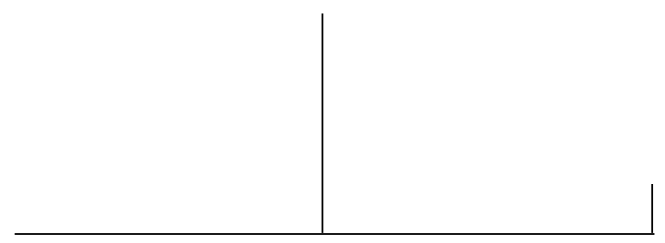

Rev. Latinoam. Psicopat. Fund., São Paulo, v. 13, n. 4, p. 585-598, dezembro 2010

\title{
Inscrições corporais: tatuagens, piercings e escarificações à luz da psicanálise*
}

Jacqueline de Oliveira Moreira

Leônia Cavalcante Teixeira

Roseane de Freitas Nicolau

O presente artigo visa apreender os discursos contemporâneos sobre o corpo pensando-o como um espaço de inscrição subjetiva. $O$ trabalho é resultado da interlocução entre pesquisas coordenadas pelas autoras em três programas de pós-graduação, cujo foco recai nos estudos acerca de diferentes modalidades de inscrições corporais. Tomando como crivo de nossas elaborações a psicanálise, enfocamos as tatuagens e as escarificações que, embora distintos, apresentam-se como formas de linguagem.

Palavras-chave: Corpo, linguagem, pós-modernidade, psicanálise

* Este trabalho é resultado de um diálogo entre pesquisadoras do Grupo de Trabalho vinculado à ANPEPP, "Dispositivos Clínicos em Saúde Mental", que aconteceu no IX Congresso Brasileiro de Psicopatologia Fundamental, em 2008. 


\section{Introdução}

Este artigo resulta da interlocução entre pesquisas coordenadas pelas autoras em três programas de pós-graduação em psicologia, cujo foco recai nos estudos acerca de diferentes modalidades de inscrições corporais na atualidade. Tais práticas corporais representam formas de manifestações de conflito psíquico ou do seu silenciamento, mas que, em última instância, consistem em modos de subjetivação. Tomando como crivo de nossas elaborações a psicanálise, enfocamos as tatuagens, os piercings e as escarificações, que embora se constituam como modos distintos de manifestação no corpo, apresentam-se como formas de linguagem que apontam para a subjetividade. $\mathrm{O}$ que dizem do sujeito estas marcas que, impressas na carne, voluntária ou involuntariamente, podem revelar algo do sujeito do desejo? Qual o estatuto do inconsciente que aí se apresenta?

As manifestações corporais como tatuagens e escarificações marcas voluntariamente impressas no corpo - são tomadas aqui como formas de linguagem implicadas com a busca de identidade e como expressão do sujeito. Popularizado em anos recentes, o hábito da tatuagem pode ser utilizado com fim simplesmente estético, ou como traço identificatório a um grupo, ou ainda, ampliando-se e repetindo-se indefinidamente até recobrir toda a superfície do corpo, como uma vã tentativa de inscrição simbólica. Um adorno como a tatuagem tem a característica de ser permanente. Mesmo removido por cirurgia plástica, dela sempre sobra uma marca, uma rasura, um rastro. $\mathrm{Na}$ proliferação excessiva da tatuagem, será possível pensar na busca de dar consistência ao corpo, ainda que pela dor? Como abordar essa pre- 
tensão de situar o sujeito para o Outro, marcar seu lugar a partir da escarificação? Enfim, o que significam essas mensagens que invadem as ruas e mesmo os consultórios?

Numa dimensão mais ampla, como os outros discursos - Filosofia, Psicologia, Antropologia - articulam a questão do corpo na contemporaneidade? Estas são questões que interessam ao psicanalista responder.

A teoria freudiana revela os efeitos do inconsciente sobre o corpo, manifestando-se por meio de sintomas conversivos ou de fenômenos ditos psicossomáticos (Volich, 2000). Se de um lado Freud construiu todo o seu edifício teórico tentando esclarecer o padecimento do corpo que escapava ao campo das explicações médicas pautadas na anátomofisiologia, de outro nos revelou a estreita articulação entre a constituição do eu e do corpo. O eu é, primeiro e acima de tudo, um eu corporal (Freud, 1923), e a dor desempenha um papel importante no bordejamento dessa identidade egóica.

A partir do entrecruzamento da Antropologia, da Filosofia e da Psicanálise destacamos o fato de que, por meio do corpo, os sujeitos podem tornar visíveis suas histórias, e ainda tentam configurar uma identidade imaginária. Entretanto, consideramos que algumas destas inscrições corporais podem também emudecer através de uma lesão não inscrita no campo simbólico. Pensamos que tais temáticas iluminam o debate sobre as práticas clínicas, contribuindo para a compreensão do pathos que nos constitui e que demanda escuta (Berlinck, 2000), já que o sofrimento, na perspectiva psicanalítica, faz parte do existir humano, não sendo algo à parte dele, do qual se possa escapar.

Parece-nos importante ressaltar algumas reflexões sobre o lugar das tatuagens e marcas voluntárias feitas no corpo na contemporaneidade. Alguns artigos pensam este tema a partir da perspectiva etnográfica e sociocultural (Perez, 2006; Ferreira, 2007). Ferreira (2007) defende a ideia de que as marcas corporais configuram formas de demarcação estilísticas e apontam para uma ética da dissidência. O corpo assumiria, nessa perspectiva, o estatuto de um operador social e as marcas representam modalidades de relações com a sociedade. Mas, faz-se urgente enfatizar que, apesar do reconhecimento da existência dessas práticas em diferentes momentos da história e em diversas culturas, os teóricos revelam uma característica própria do mundo contemporâneo no que se refere à relação do sujeito com o ato de colocar piercing e fazer tatuagem ou escarificações que, por vezes, podem estar relacionada com embelezamento (Leitão, 2004); ou puramente com arte, ou seja, as tatuagens como suporte para arte (Pires, 2003).

Costa (2003) revela que as leituras sobre as marcas corporais produzidas pelas tatuagens e piercing não conseguem responder a indagação: "Por que os homens começaram a tatuar-se, a fazer piercing, escarificar-se ou mesmo mutilar-se?" (p. 10).

Rev. Latinoam. Psicopat. Fund., São Paulo, v. 13, n. 4, p. 585-598, dezembro 2010 


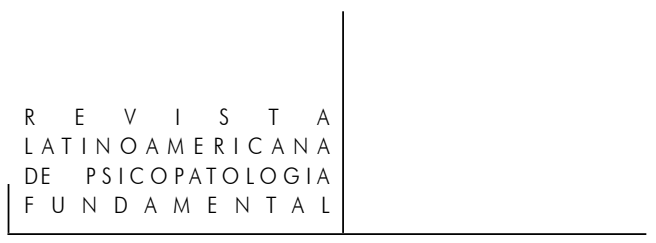

Costa (2003) propõe um diálogo com a psicanálise para pensar as marcas corporais, mas alerta para a escassez de bibliografia sobre o tema e para os perigos de supervalorizar a incidência dessa prática no mundo contemporâneo, pois as tatuagens e piercings remontam à história da humanidade e aparecem em diferentes culturas. Para a autora as tatuagens, piercings e escarificações são marcas que buscam fazer borda, “... são recortes que têm a ver com a erotização e sua necessidade de suporte no Outro" (p. 17). Nesse sentido, salientamos a importância de "escutar" tais práticas como relacionadas à constituição psíquica, já que parecem remontar a momentos precoces da construção do eu nos quais a superfície da pele constitui espaço de inscrição psíquica. É interessante ressaltar que as várias modalidades de perfurações corporais, apesar de resultarem em formas distintas de marcas, fazem incidir bordeamentos sobre a pele. Podemos pensar que esse bordeamento possui um caráter erótico, pois ao desenhar diferentes delineamentos na superfície corporal sensibilizam zonas que passam a ser eróticas.

Lacan liga a tatuagem com uma função erótica (Costa, 2003, p. 18). Tomada desta perspectiva, a tatuagem e a escarificação são formas primeiras de encarnar, no corpo, esse órgão irreal que é a libido. Lacan refere-se à libido como órgão irreal, que pede o mito, e diz que uma das formas mais antigas de se encarnar no corpo esse órgão irreal é a tatuagem e a escarificação que viria situar o sujeito para o outro. Aqui, "o entalhe tem a função de ser para o Outro e, deste modo, possibilita situar o sujeito, marcando seu lugar no campo das relações do grupo, entre cada um e todos os outros" (Lacan, 1988, p. 195). Ressalta-se aí seu aspecto de ordenação, e o acento recai sobre sua função erótica.

Por outro lado, Lacan também chama atenção para o fato de que, tão antiga e estrutural quanto o fascínio exercido pela forma humana, é a utilização do corpo como suporte para o significante, o que nos remete ao processo de constituição subjetiva. Segundo ele, "Nossa presença de corpo animal é o primeiro lugar onde colocar inscrições: o primeiro significante" (p. 195). Neste aspecto, Lacan se refere ao corpo como lugar das cicatrizes, feito para inscrever algo que se chama a marca, sendo feito para ser marcado pelo Outro, campo onde o sujeito se constitui. Faz, igualmente, uma comparação da tatuagem com o traço unário: "O traço unário, o próprio sujeito a ele se refere, e inicialmente ele se marca como tatuagem, o primeiro dos significantes" (p. 135). O traço unário é o que vem possibilitar o advento do sujeito, esse que emerge pontualmente entre um significante e outro. Nesse aspecto é que podemos dizer que a tatuagem, assim como as escarificações, relaciona-se à constituição subjetiva, funcionando como suporte da identificação imaginária.

Cabe ainda ressaltar a importância da dor na feitura das tatuagens e das demais formas de perfuração da pele, como os piercings e as escarificações, salien-

Rev. Latinoam. Psicopat. Fund., São Paulo, v. 13, n. 4, p. 585-598, dezembro 2010 
tando o lugar do masoquismo como constituinte de um novo desenho corporal, uma nova pele, uma segunda pele.

Ressaltamos que as perspectivas psicanalíticas não diferenciam psíquico e somático, tratando-os como registros, não excludentes, de expressão do pathos. São modos de sofrer singulares que se forjam dialeticamente nas modalidades de organização do excesso que o social constrói e que caracteriza o pathologico (Berlinck, 2000). A existência comporta subjetivações que ora acompanham as ordenações sociais, culturais, morais, jurídicas e científicas, nelas se inserindo e delas recebendo aval de pertinência e normalidade, ora não se encontram em consonância com o normal entendido por critérios estatísticos normatizadores. As subjetividades que ficam à margem do hegemônico, que se constituem pelo excesso e pela exuberância, são consideradas pela psicanálise não como patológicas, no sentido da racionalidade médica que se centra nos conceitos de doença e de disfunção como desvios e como alheias ao humano, mas como constituintes de seu estofo.

Nesse sentido, a experiência corporal envolve processos complexos de investimentos, desinvestimentos e reinvestimentos narcísicos, movimentos pulsionais eróticos e tanáticos que reinscrevem o sujeito nos momentos lógicos do autoerotismo e do narcisismo - implicando-o regressivamente em posições subjetivas arcaicas -, bem como mobilizam posições masoquistas à custa da economia psíquica centrada no gozar e não na lógica do desejo (Freud, 1926). O adoecimento, por exemplo, pode consistir em produção do inconsciente, daí sua implicação com o sujeito, não se restringindo a explicações causais atributivas à genética, ao meio externo, aos modos de vida. A doença e suas nuanças trazem a marca do sujeito, de sua constituição, de sua inserção na trama simbólica, de como se situa frente à linhagem e ao outro a partir dos jogos identificatórios que produzem traços identitários, de acordo com os quais se situa, no social, como realidade factual (Freud, 1926; Teixeira, 2001). No mesmo sentido, apreendemos as práticas corporais que se constroem no campo das automutilações, como as tatuagens, os piercings, as escarificações que, ao marcar o corpo em sua superfície, fazem marca psíquica, criando orifícios e bordas. Depreendemos, assim, que, em experiências incitadas por intervenções modificadoras do corpo, os sujeitos procuram afirmar os seus limites, bem como vivenciar as diversas possibilidades de sensações e imagens, como, por exemplo, fabricando novos orifícios, contornos e desenhando novas zonas de sensibilidade erótica (Costa, 2004).

Em suma, na atualidade o corpo é pensado em sua plasticidade para, assim, expressar as diversidades históricas e subjetivas. As transformações que o humano realiza no corpo, portanto, representam não só os traços narcísicos, hedonistas e consumistas das sociedades contemporâneas, mas, prioritariamente, maneiras 


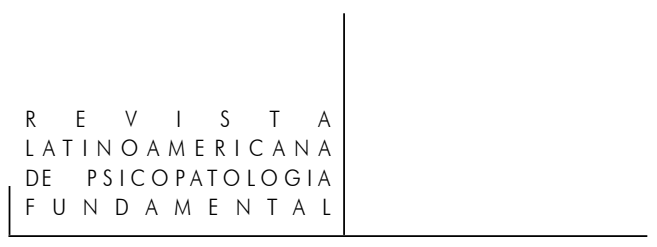

de o sujeito se constituir subjetivamente, o que demanda um olhar diferenciado daquele que as teorias sobre o social lhe endereçam. Neste texto, visamos apreender os discursos contemporâneos sobre o corpo, neles contextualizando as modalidades de constituição subjetiva pelas marcas corporais.

\section{A emergência do corpo nos discursos contemporâneos}

A presença de inscrições no corpo, seja por intermédio de tatuagens ou de escarificações, e o aparecimento de sintomas corporais que traduzem sofrimentos eminentemente psíquicos, destaca-se cada vez mais na contemporaneidade. $\mathrm{Na}$ verdade, o corpo passa a ocupar um espaço privilegiado de manifestação e comunicação de conflitos psíquicos. Cabe, então, pensarmos por que ele se tornou um objeto de estudo de diferentes campos do saber, como a Psicologia, a Psicanálise, a História e Antropologia; pois, a tradição filosófica cartesiana atribuía ao corpo um lugar secundário (Courtine, 2008). Quais as modificações ocorridas na tradição racionalista cartesiana para que hoje possamos pensar o corpo como indissociável do sujeito? Segundo Courtine, o corpo foi inventado teoricamente no século XX, e seria Freud o grande responsável por sua nova percepção. A teoria freudiana propõe pensá-lo para além da carnalidade; o corpo não é apenas um organismo biológico. Ele é atravessado pela linguagem, e essa, por sua vez, faz com que o corpo exista fora da pura sensação carnal. As oscilações psíquicas produziram efeitos no corpo e no psíquico que, por sua vez, sofrem influências do ambiente social. De outro lado, a percepção do corpo está associada às noções de tempo e de espaço, pois o corpo ocupa um lugar no espaço e no tempo, sendo este histórico e individual. O tempo individual do corpo refere-se ao ritmo. Assim, uma aceleração do ritmo produzirá efeitos no corpo. Não podemos deixar de mencionar que, na pós-modernidade, vivemos uma maneira singular de relação com a dimensão do tempo, que se difere das formas modernas e pré-modernas, produzindo inovações na relação com o corpo próprio.

A passagem da pré-modernidade para a modernidade é marcada pela ruptura com as tradições. Segundo Renaut (1998), o traço mais específico das sociedades modernas é a contínua dissolução das referências oriundas do passado (p. 31). O homem pré-moderno voltava-se para seu passado, encontrava neste uma referência normativa para seu presente. A modernidade opera uma ruptura com a tradição; os valores do passado parecem estar singularmente enfraquecidos em benefício da celebração do presente e do novo (p. 36). Drawin (2003) afirma que o homem moderno volta-se para o futuro e busca neste as referências normativas de sua vida. O desenvolvimento da ciência moderna produz nos sujeitos uma

Rev. Latinoam. Psicopat. Fund., São Paulo, v. 13, n. 4, p. 585-598, dezembro 2010 
aposta no futuro. Assim, o homem pré-moderno e o moderno situam-se na trama temporal da história, na certeza do movimento limitador do tempo.

A pós-modernidade é caracterizada pela ruptura, pelo desrespeito com o vínculo temporal com o passado e/ou com o futuro (Drawin, 2003). Vive-se a imediaticidade do agora; não há História, pois não importa o passado ou o futuro, adquirindo o presente uma dimensão tirânica e perversa. O futuro deixou de ser uma aposta, o passado não é respeitado como referencial, só restando a vacuidade do presente (Bauman, 1998; Costa, 2004; Le Breton, 2003). Sem raízes no passado e sem perspectiva futura resta ao sujeito pós-moderno o seu corpo como realidade incontestável (Le Breton, 2003; Ortega, 2003).

Não podemos negar que cada época produz seu mal-estar específico. Para Bauman (1998),

... os mal-estares da modernidade provinham de uma espécie de segurança que tolerava uma liberdade pequena demais na busca da felicidade individual. Os mal-estares da pós-modernidade provêm de uma espécie de liberdade de procura do prazer que tolera uma segurança individual pequena demais. (p. 10)

Essa mudança da felicidade para o prazer ilimitado comporta um sofrimento que, na teoria lacaniana, nomeamos gozo. Lacan refere-se ao gozo como a satisfação de uma pulsão, estando sempre implicada com o corpo. Isso coloca o corpo como cenário privilegiado das formas de existir subjetivas (Costa, 1988, 2004; Ortega, 2003).

\section{O que dizem as marcas no corpo?}

A partir da discussão acima, é interessante pensar na proliferação de tatuagens, seja com o nome do parceiro, seja como marcas de um momento ou como puro enfeite. Nesse último caso a pele é um adorno que pode ser colorido e apresentado como tela, bem como uma superfície que se impõe ao ser marcada por orifícios fabricados nos quais são injetados coloração. É pensando que tais práticas de tatuagem, piercing e escarificações demandam uma escuta não redutora de suas polissemias, que afirmamos ser no corpo que se inscreve, literalmente, a história do sujeito. O sujeito se esforça para exteriorizar seus afetos, fantasias e desejos. O corpo, nesse sentido, funciona como um meio de comunicação. A partir do excesso de informações, o bombardeio de estímulos deixa o sujeito mudo, mas seu corpo fala por meio das tatuagens, piercings e outras obras. Considerando tais nuanças, privilegiamos o olhar da psicanálise, por considerá-lo acolhedor a essas modalidades de constituição subjetiva que não se acomodam facilmente aos padrões de subjetivação hegemônicos. 


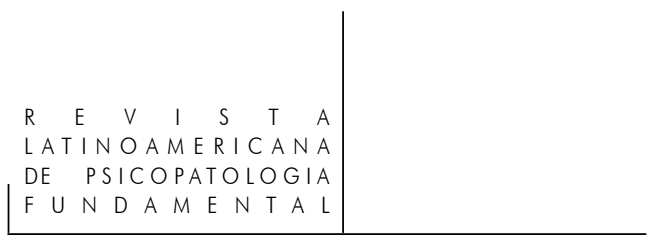

Podemos pensar que a tatuagem, o piercing e as obras no corpo oferecem para o sujeito uma identidade de superfície. O próprio corpo e, sobretudo, a sua superfície, constituem um lugar privilegiado de sensações, estabelecendo, pois, um limite sensoperceptivo delineador de uma unidade. Freud (1923) revela que a dor desempenha um papel importante nesse processo de demarcação do eu, pois, as doenças dolorosas constituem talvez um modelo da maneira pela qual em geral chegamos à ideia de nosso corpo (p. 39). Essas marcas no corpo definem fronteiras objetivas e subjetivas, porque além de demarcarem os limites concretos do corpo, possibilitam a filiação a grupos a partir das marcas corporais. Podemos encontrar o grupo dos tatuados contestadores e o grupo da adoração estética à beleza.

Porém, guardada as diferenças entre os grupos não podemos negar que as tatuagens convidam à perspectiva das sensações e percepções. Freud (1923) vincula o eu ao corpo revelando ser na superfície, ou seja, na pele, que se originam as sensações internas e externas. Assim, o tato produz uma sensação que equivale à percepção interna de si como uma unidade. Podemos pensar que as marcas no corpo possibilitam uma vivência sensorial que, no ato de sua criação, unem dor e prazer e criam as bordas de um eu/pele. Mas, para além deste prazer, podemos pensar em um prazer que convida o par escopofilia/exibicionismo. Segundo Le Breton (2003), as marcas corporais implicam igualmente uma vontade de atrair o olhar, de fabricar uma estética da presença (p. 40). A utilização da expressão para além não foi acidental. Pensamos que as marcas corporais podem, por vezes, estar vinculadas à pulsão de morte, ou seja, são marcas reais daquilo que ultrapassa o campo da representação. Assim, as marcas podem ser tentativas de bordejar as angústias inomináveis e impensáveis que habitam o ser, ou mesmo de negar essas angústias primordiais, pois o corpo todo tatuado pode deixar de ser corpo para ser tela, livro. Algo que me faça esquecer a condição de finito, pois o corpo é a maior lembrança deste estado.

Assim, acreditamos que por detrás de um fenômeno de moda encontramos modos de subjetivação que respondem às circunstâncias socio-históricas. Não podemos negar que a paixão repentina pelo corpo é resultado do individualismo que se expressa por meio da cultura do Narcisismo (Lasch, 1983) e da sociedade da performance (Debord, 1997). Essa nova forma de organizar o corpo guarda uma aura particular e quase divina. Para Ortega (2003), as inscrições no corpo apontam para uma falência do simbólico e, desta forma, emerge uma necessidade de registrar no real os acontecimentos, dispensando, pois, as palavras.

As modificações corporais constituem uma radicalização do real: quando a ordem simbólica não produz mais a ordem social, o simbólico é reduzido ao real, ele é incorporado, encarnado. A passagem do simbólico ao real acontece pelo e

Rev. Latinoam. Psicopat. Fund., São Paulo, v. 13, n. 4, p. 585-598, dezembro 2010 
no corpo. A autenticidade e a realidade são materializadas na marca corporal como uma forma de existir que dispense as palavras e o olhar do outro, os quais não são confiáveis... (p. 6)

Para Ortega (2004), as marcas no corpo revelam uma falência do simbólico e a construção de uma ficção de liberdade. O autor anuncia “... não podendo mudar o mundo, tentamos mudar o corpo, o único espaço que restou à utopia, à criação. As utopias corporais substituem as utopias sociais" (p. 252). Ferreira (2007) não compactua com essa posição que pensa as marcas no corpo como um projeto inteiramente "apolítico". Fundamentando-se em uma base foucaultiana, Ferreira considera que "embora se faça passar por um projeto ensimesmado, permanecendo firmemente entrincheirado numa políticad e vida que luta por um espaço de singularidade e liberdade individual" (p. 318).

\section{Considerações finais}

Assistimos, na atualidade, à elaboração de discursos sociais que buscam normatizar o corpo humano, como, por exemplo, o discurso científico sobre a perfeição e a completude do mesmo (Da Poian, 2000; Ortega, 2003; Roudinesco, 2000). Assim como nos explicou Foucault (1996), o poder incide diretamente nos corpos dos sujeitos, realizando a sujeição de suas forças e lhes impondo uma relação de docilidade-utilidade, isto é, de disciplina. Observamos com o autor que o corpo, ao longo das organizações sociais, produz formas de reação à disciplina imposta pelos discursos normatizadores, ocorrendo nesta ação e reação entre o corpo e as instituições de poder o processo civilizatório.

Se advogamos o argumento de que há uma reação da subjetividade à normatização, aludimos que há, também, uma relação entre as formas de se subjetivar e o contexto social em que se está inserido. Desta maneira, compreendemos que a subjetividade é uma construção social e isto significa que o corpo ganha novos sentidos e os expressam de forma diferente a cada época. A produção de novos discursos sociais, a que assistimos na atualidade, acontece, simultaneamente, à produção de novas formas de subjetivação.

Extraímos de Lipovetsky (2005) a lição de que, na sociedade atual, o discurso social não se articula mais pela disciplina e pela autoridade, e sim pelo "poder da sedução". Isso significa que a ordem social incide nos corpos, seduzindo-os a serem sempre belos, ativos, saudáveis, jovens e sensuais. Devem se prender a um único tempo, o do presente, silenciando as instâncias do passado e do futuro. Com isto, o que importa é o prazer e as sensações sentidas no aqui-e-agora, perdendo valor tudo o que diz respeito à tradição, à história e aos costumes. Nesta

Rev. Latinoam. Psicopat. Fund., São Paulo, v. 13, n. 4, p. 585-598, dezembro 2010 
perspectiva, os discursos midiáticos e médico sobre a perfeição dos corpos são os que se posicionam como referenciais dos sujeitos na atualidade (Costa, 2004; Da Poian, 2000).

$\mathrm{Na}$ atualidade, enquanto o sujeito é convocado através da experiência corporal a movimentar-se em busca da perfeição e completude, constroem-se modalidades de experiência subjetiva, como as acima descritas, que questionam a hegemonia dos discursos normalizadores da ciência e da mídia. Percebemos que esta ação não ocorre pelo reconhecimento da impossibilidade da satisfação irrestrita, e sim pela crença em discursos hegemônicos sobre a possibilidade de um dia conquistar a perfeição corporal e a felicidade plena (Andrade e Bosi, 2003). O sujeito se põe em constante batalha consigo mesmo não apenas para amenizar o seu desamparo, mas para ilusoriamente bani-lo de sua existência, permitindo com que ele tome posse de um corpo sem limites e plenamente satisfeito (Da Poian, 2000). Na impossibilidade de conquistar este ideal de felicidade - tão bem anunciado e vendido na sociedade atual - o sujeito contemporâneo acaba por ser acometido por uma profunda e intensa frustração.

\section{4}

\section{Referências}

Andrade, A.; Bosi, M. L. Mídia e subjetividade: impacto no comportamento alimentar feminino. Revista de Nutrição, Campinas, v. 6, n. 1, p. 117-125, mar. 2003.

Baudrillard, J. O sistema dos objetos. São Paulo: Perspectiva, 1998.

Bauman, Z. O mal-estar da pós-modernidade. Rio de Janeiro: Jorge Zahar, 1998.

Berlinck, M. T. Psicopatologia fundamental. São Paulo: Escuta, 2000.

Costa, A. Tatuagens e marcas corporais: atualização do sagrado. São Paulo: Casa do Psicólogo, 2003.

Costa, J. F. Narcisismo em tempos sombrios. In: BiRman, J. (Org.). Percursos na história da psicanálise. Rio de Janeiro: Taurus, 1988. p. 151-174.

O vestígio e a aura: corpo e consumismo na moral do espetáculo. Rio de Janeiro: Garamond, 2004.

Courtine, J. J.; Corbin, A.; Vigarello, G. História do corpo. Petrópolis: Vozes, 2008. v. 3 (As mutações do olhar: século XX).

Da Poian, C. Inquietações contemporâneas: formas do vazio. Cadernos de Psicanálise do Círculo Psicanalítico do Rio de Janeiro, Rio de Janeiro, v. 21, n. 14, p. 53-66, 2000.

Debord, G. A sociedade do espetáculo. Rio de Janeiro: Contraponto, 1997.

Rev. Latinoam. Psicopat. Fund., São Paulo, v. 13, n. 4, p. 585-598, dezembro 2010 
Drawin, C. R. O futuro da psicologia: compromisso ético no pluralismo. In: Bock, A. M. B. (Org.). Psicologia e o compromisso social. São Paulo: Cortez, 2003. p. 55-72.

Ferreira, V. S. Política do corpo e política de vida: a tatuagem e o body piercing como expressão corporal de uma ética da dissidência. Etnográfica, v. 11. n. 2, p. 291326, 2007.

Foucault, M. Microfísica do poder. Rio de Janeiro: Graal, 1996.

Freud, S. (1905). Três ensaios sobre a teoria da sexualidade. In: Edição Standard Brasileira das Obras Psicológicas Completas de Sigmund Freud. Rio de Janeiro: Imago, 1976. v. VII.

. (1915). Os instintos e suas vicissitudes. In: Edição Standard Brasileira das Obras Psicológicas Completas de Sigmund Freud. Rio de Janeiro: Imago, 1976. v. XIV.

. (1920). Mais além do princípio do prazer. In: Edição Standard Brasileira das Obras Psicológicas Completas de Sigmund Freud. Rio de Janeiro: Imago, 1976. v. XVIII.

. (1923). O ego e o Id. O ego e o id, uma neurose demoníaca do século XVII e outros trabalhos. In: Edição Standard Brasileira das Obras Psicológicas Completas de Sigmund Freud. Rio de Janeiro: Imago, 1976. v. XIX, p. 13-86.

. (1926). Inibição, sintoma e ansiedade. Dum estudo autobiográfico: inibição, sintoma e ansiedade, a questão da análise leiga e outros trabalhos. In: Edição Standard Brasileira das Obras Psicológicas Completas de Sigmund Freud. Rio de Janeiro: Imago, 1976. v. XX, p. 95-204.

. (1930[1929]). Mal-estar na civilização. In: Edição Standard Brasileira das Obras Psicológicas Completas de Sigmund Freud. Rio de Janeiro: Imago, 1976. v. XXI.

LaCAN, J. O seminário. Livro 11. Os quatro conceitos fundamentais da psicanálise. Rio de Janeiro: Jorge Zahar, 1988.

Lasch, C. A cultura do narcisismo. Rio de Janeiro: Imago, 1983.

Le Breton, D. Adeus ao corpo: antropologia e sociedade. Campinas, SP: Papirus, 2003.

LEITÃo, D. K. Mudança de significado da tatuagem contemporânea. Cadernos IHU Ideias, Rio Grande do Sul, v. 2, n. 16, 2004. Disponível em: <http://www.unisinos.br/ ihu/uploads/publicacoes/edicoes/1163186745.46pdf.pdf > . Acesso em: 12/10/2009.

Lipovetsky, G. A era do vazio: ensaios sobre o individualismo contemporâneo.

Barueri, SP: Manole, 2005.

Ortega, F. Modificações corporais e bioidentidades. Revista de Comunicação e Linguagens, Lisboa, n. 33, p. 247-263, 2004.

Rev. Latinoam. Psicopat. Fund., São Paulo, v. 13, n. 4, p. 585-598, dezembro 2010 
Utopias corporais substituindo utopias sociais: identidades somáticas e marcas corporais na cultura contemporânea. Apresentado no XII Encontro Nacional da Associação Brasileira de Psicologia Social. Porto Alegre, out. 2003.

Perez, A. L. A identidade à flor da pele: etnografia da prática da tatuagem na contemporaneidade. Mana, Rio de Janeiro, v. 12, n. 1, abr. 2006 . Disponível em: <http:// www.scielo.br/scielo.php?script=sci_arttext\&pid=S0104 93132006000100007 \&lng= en\&nrm=iso>. Acesso em: 13 out. 2009. doi: 10.1590/S0104-93132006000100007

PIRES, B. F. O corpo como suporte da arte: piercing, implante, escarificação, tatuagem. São Paulo: Editora Senac, 2003.

Renaut, A. O indivíduo: reflexões acerca da filosofia do sujeito. Rio de Janeiro: Difel, 1998.

Roudinesco, E. Por que a psicanálise? Rio de Janeiro: Jorge Zahar, 2000.

Volich, R. M. Psicossomática. São Paulo: Casa do Psicólogo, 2000.

\section{Resumos}

(Body inscriptions: tattoos, piercing and scraping in the light of psychoanalysis)

This article is an attempt to apprehend contemporary discourses about the body and see this body as a space for subjective inscription. The article is the result of the interlocution among research projects that focus on the study of different types of body inscription and that are coordinated by the authors at three graduate programs. Taking psychoanalysis as the basis for our discussions, we study tattoos and scraping which, however distinct, are both seen as forms of language.

Key words: Body, language, post-modernity, psychoanalysis

(Inscriptions corporelles: tatouages, piercings, scarifications à la lumière de la psychanalyse)

Cet article vise à analyser les discours contemporains sur le corps en l'interprétant comme un espace d'inscription subjective. Ce travail est le résultat d'une interaction entre des recherches coordonnées par les auteurs dans trois projets de recherche au niveau doctoral concernant les différentes sortes d'inscriptions corporelles. En prenant la psychanalyse comme point d'ancrage de nos considérations, nous abordons les tatouages et las scarifications, bien que distincts, comme une sorte de langage.

Mots clés: Corps, langage, postmodernité, psychanalyse 
(Inscripciones corporales: tatuajes, piercings y escarificaciones a la luz del psicoanálisis)

El presente artigo visa aprehender los discursos contemporáneos sobre el cuerpo, pensándolo como un espacio de inscripción subjetiva. El trabajo es resultado de la interlocución entre investigaciones coordenadas por las autoras en tres programas de posgrado, cuyo foco recae en los estudios acerca de diferentes modalidades de inscripciones corporales. Adoptando como criterio de nuestras elaboraciones el psicoanálisis, enfocamos los tatuajes y las escarificaciones, que a pesar de distintos, se presentan como formas de lenguaje.

Palabras clave: Cuerpo, lenguaje, posmodernidad, psicoanálisis

Citação/Citation: MoreIRA, J.O; TeIXEIRA, L.C.; NicolaU, R.F. Inscrições corporais: tatuagens, piercings e escarificações à luz da psicanálise. Revista Latinoamericana de Psicopatologia Fundamental, São Paulo, v. 13, n. 4, p. 585-598, dez. 2010.

Editor do artigo/Editor: Prof. Dr. Manoel Tosta Berlinck

Recebido/Received: 9.8.2009/ 8.9.2009 Aceito/Accepted: 23.9.2009/9.23.2009

Copyright: (C) 2009 Associação Universitária de Pesquisa em Psicopatologia Fundamental/ University Association for Research in Fundamental Psychopathology. Este é um artigo de livre acesso, que permite uso irrestrito, distribuição e reprodução em qualquer meio, desde que o autor e a fonte sejam citados/This is an open-access article, which permits unrestricted use, distribution, and reproduction in any medium, provided the original author and source are credited.

Financiamento/Funding: As autoras declaram não ter sido financiadas ou apoiadas/The authors have no support or funding to report.

Conflito de interesses/Conflict of interest: As autoras declaram que não há conflito de interesses/The authors declare that has no conflict of interest.

\section{JacQueline de Oliveira Moreira}

Psicóloga; doutora em Psicologia Clínica pela Pontifícia Universidade Católica de São Paulo - PUC-SP (São Paulo, SP, Brasil); mestre em Filosofia pela Universidade Federal de Minas Gerais - UFMG (Belo Horizonte, MG, Brasil); professora do mestrado em Psicologia da Pontifícia Universidade Católica de Minas Gerais - PUC-MG (Belo Horizonte, MG, Brasil) (filiado à ANPEPP)

Rua Congonhas, 161 - São Pedro 30330-100 Belo Horizonte, MG, Brasil

Fone: (31) 3223-3951

e-mail: jackdrawin@yahoo.com.br

Rev. Latinoam. Psicopat. Fund., São Paulo, v. 13, n. 4, p. 585-598, dezembro 2010 


\section{Leônia Cavalcante Teixeira (UNIFOR)}

Psicóloga; professora do Programa de Mestrado em Psicologia da Universidade de Fortaleza (Fortaleza, CE, Brasil) filiado à ANPEPP

Rua Alfeu Aboim, 55 - Papicu

60175-375 Fortaleza, CE, Brasil

Fone: (85) 3234-1299

e-mails: leoniat@unifor.br, leoniat@uol.com.br

\section{Roseane Freitas Nicolau}

Psicóloga; psicanalista; professora do Programa de Pós-graduação em Psicologia Clínica e Social da Universidade Federal do Pará - UFPA (Belém, PA, Brasil) (filiado à ANPEPP). R. dos Mundurucus, 1553/501 66035-360 Belém, PA

Fone: (91) 3222-7316 / 8141-6936

e-mail: rf-nicolau@uol.com.br 